pective between those primarily concerned with the management and improvement of an existing production system and those concerned with potential changes in products and processes including the total displacement of existing systems. However, there seems little doubt that the problem was particularly acute in the Soviet Union as institutional barriers were reinforced by geographical and political constraints. Lewis shows that, despite many declarations of good intentions about decentralization, the R\&D establishment remained overwhelmingly concentrated in the Moscow and Leningrad regions. He calculates that a decade of pressure resulted only in a reduction of the proportion employed in these two regions from $80 \%$ to $75 \%$. Again, this is by no means exclusively a Soviet problem.

The final chapters suggest, although not very explicitly, that the most important specific Soviet weakness has been the overcentralization of decision-making associated with Stalinism. It is of some interest that already in the 1920s Pyatakov and other members of the "Left" opposition were advocating the wholesale decentralization of industrial $R \& D$ to the enterprise level. The combination of the output target system, the import of 'turnkey' foreign technology, the shortages of skilled people and the decimation of the intelligentsia in the purges of the 1930s meant that the various attempts which were made to strengthen enterprise-level $R \& D$ had little effect.

The major exception which Lewis points to was the aircraft industry, and the discussion of its peculiarities in Chapter 9 is one of the most interesting in the whole book. This industry was a high priority for the leadership throughout the 1920 s and 1930s which found expression both in a relatively lavish level of funding and in a readiness to change the organizational system in order to get the results so urgently demanded by Stalin and other leaders, who apparently showed an almost daily interest. Whereas in other industries it was difficult to get adequate resources for prototype and pilot plant work, in the aircraft industry several alternative designs were often promoted simultaneously right through to the prototype test stage in development. In the aircraft industry too, the single central research and design institute gave birth to a pluralistic structure already in the early 1930s which included the rather successful flexible design groups assembled under the leadership of individual designers and sometimes located at factories.

Centralization to a high degree certainly persisted in the aircraft industry, but it was combined with a real choice in design and development based on autonomous effort and with relatively good communications with the production systems. An interesting point made by Lewis is that sometimes factory personnel were brought into the design and development teams at a fairly

early stage. He does not discuss it, but one may guess that this industry also made good use of its own products to ease the physical communication problems of the USSR.

By preventing Germany and Japan from embarking on expensive aircraft, nuclear and other military R\&D projects for two decades after the Second World War, the USSR and its War-time allies conferred upon them the inestimable blessing of concentrating most of their best engineering and scientific talent on the industries which really mattered for economic growth and international trade performance. The results are now increasingly apparent. The British in a mild way since 1945 have suffered from the Russian problems of the 1930 s - too high a priority for $R \& D$ in prestige defencerelated industries and relative neglect of the

Christopher Freeman is Director of the Science Policy Research Unit, University of Sussex, Brighton, UK.

\section{Voyages through the cosmic landscape}

\section{D.D. Clayton}

Cosmic Landscape: Voyages Back Along the Photon's Track. By Michael RowanRobinson. Pp.149. (Oxford University Press: Oxford and New York, 1980.) £4.50.

WHEN I began this book I was somewhat prejudiced against it because I thought it would sink from the burden of its seemingly unnatural standpoint. After all, astronomical knowledge has exploded from the combined measurements of astronomical objects by instruments responsive to the different spectral bands. Yet, here Michael Rowan-Robinson presents "cosmic voyages in each of the main wavelength bands of contemporary astronomy". He finds himself "taking this metaphor of voyage literally, and describing how I think things would look from a viewpoint different to that seen from earth. Certain objects in the cosmic landscape figure in several different wavelength bands and so our picture of them builds up only gradually from the succession of voyages in each band'. Surely, I thought, the only way to discuss the Crab Nebula, or QSO 3C 273, would be from the simultaneous knowledge from all types of measurements, and not from a succession of half-blind glimpses. But in the end my negative predisposition was overcome by an informative and often poetic presentation. This is a very good book, although it fails by slim margins to be a great one. rest. As in the USSR, a very high proportion of our best science and engineering talent was locked into this system for 30 years, while the mechanical engineering industries, vehicles and other mundane branches of the economy did not have the capacity to design and develop new products to keep pace with world competition. To this day, they do not have and often cannot get the electronic engineers they need to re-design their products and processes. It would be ironical if the 'Iron Lady' in her anxiety to combat the Soviet 'menace' caught a more virulent strain of the Russian'flu.
The author says, "I have tried to write a book for someone who might never have read anything about astronomy". So restricted, he must at times be a teacher: "What is light?"; "What is colour?"; "How is light made?"; "What are radio waves?" are subsections of chapters in which he must also explain such phenomena as atomic and molecular structure and radioactivity without seeming to delay forever the departure of the cosmic expresses. Amazingly, he has surmounted this obstacle with as much grace as one can hope for. He does this by appealing to general matters of human interest - for example, by describing briefly the red, green and blue-light-sensitive organic pigments in the cone-shaped detector on the back of the human retina. Occasionally, he forgets this audience and uses technical terminology that can only impede the novice; for example, because he uses it he must explain that in writing $\mathrm{O}$ VI "the Roman numeral corresponds to one more than the number of missing electrons". The book is, I think, a bit difficult for readers without scientific backgrounds; but the author has made a good compromise between simplicity and the inspiration of real intellectual content. For this reason, I will recommend this book to nonprofessionals interested in astronomy, even knowing they will not understand some of it.

So we set off in succession on six voyages: the visible landscape; the radio landscape; the ultraviolet landscape; the Xand $\gamma$-ray landscape; the infrared landscape; and the microwave landscape. I could not discern the author's reason for this order; but neither can I criticize it as illogical or inappropriate. Perhaps putting the infrared landscape off until the fifth voyage has something to do with the author's personal research emphasis. It warms him especially to this voyage, causing him to note here, almost sadly, that totally new surveys of the sky seem to be 
now a part of history, and then to the confession: "For me it has been a wonderful time to be alive and to be an astronomer. And so $I$ try to share this experience with you'".

To analyse the success of this book I must, like the author, branch out from astronomy into the larger realm of human experience. A landscape is interpreted as a partly subjective human experience, with the human at its centre. Its objective, in an artistic sense, is not the description of the separate parts of the scenery, but rather a description of the act of perceiving it. Rowan-Robinson has not idly chosen a catchy title; he has chosen it specifically to his artistic purpose. The ponderous structure of separate voyages in different wavelength bands succeeds because his purpose is not to explain our understanding of the objects in the landscapes, but rather the human act of perceiving them. He evokes, perhaps unintentionally, the experience of the child in its crib, looking out at baubles hanging above him and wondering at the meaning of a perception he cannot touch. It is a powerful undercurrent that gives force, by its repetition, to these cosmic voyages. The reader glimpses the human race in its infancy, reaching out.

I cannot say that Rowan-Robinson intended all of this, but I believe that he did. As someone who has also attempted to enlarge the genre of scientific writing, I can only admire his effort. It falls short of greatness because the author was not sufficiently single-minded in this task. The pedagogical explanations weigh down the poetic experience. We have here the artist painting his landscape and, at the same time, explaining to us how we know that the water in the creek flows downhill rather than up. On the positive side of that coin, however, there is fascinating astronomical and physical knowledge interestingly described on each page. So it is also a book from which to learn about astronomy. For a skilful blend of these objectives, the author earns grade A. I remain fascinated with the partially fulfilled opportunities of this book as a poetic and artistic experience. I can best share this fascination by the following poem, which this book inspired me to write:

\section{On His Reading Cosmic Landscape}

Hanging there on strings, tiny baubles above my crib, What would I name you if I, like they, knew words? Jupiter, Venus, pulsar, quasi-stellar objects of my gaze, Abstaining from warm flesh from which I grew,

You surely breathe and eat and cry like $\mathrm{I}$.

For what can I now know of death, of that passage

That will one day threaten the incomprehensible world?

Silently they hang above me, beyond my reach, unreal . . .

Unreal at least except for eyes, mystical extensions,

Touch without fingers, motion without impact, something there,

But maybe not important, milkless, without warmth.

Still, you must have a name, a kind of category,

Something that can let me live at peace with you.

Could I but sense you in my way, some measure perhaps,

Could I but bridge the gulf that lies between,

Maybe I would do so, but how? what do I need?

A name is fine, but will it shore up liberty

From ignorance, from lack of touch, from measurement?

From measurement! What new idea now swarms within me?

Perhaps a mathematics, calculations from untouchables

Can clarify your orbit, predicting perigee perhaps or self collapse.

Unending accusations drain this dream: worthless metaphysics,

Not a method to trust, yet my heart does beat to it.

Have ancient genes bestowed on me this thrill,

Forgotten values to mankind accrued to permanence in me?

Urging explorations, voyages from this nursery,

They inflame my nerves where comfort never can.

Rattlesnakes see infrared and suffer no abject demise,

Bats somehow hear a soundless noise, compressibilities,

But all the same to me, here, not knowing, ignorant,

Wondering simply what it means to see beyond,

And if this oh-so-childish room will stand the test

Of time, when I no longer am its nexus.

D.D. Clayton, 1980

\section{An optimist's selection of nightmares}

\section{Peter J. Smith}

A Choice of Catastrophes. By I. Asimov. Pp. 377. (Simon and Schuster: New York, 1979.) \$11.95.

IMAGINE a small black hole about the size of the average asteroid and with a mass of, say, a millionth of that of the Earth. Suppose then that this remarkable object were to enter the Solar System and score a direct hit on the Earth. What would the result be? The "mini-black hole" would tunnel its way into the planet, absorbing matter and thus growing as it went. If it had sufficient momentum to begin with, it would burn a path right through the Earth, causing enormous explosions where it entered and left. At the points of entry and departure life would stand little chance of survival, although the Earth itself would probably heal and go on as before.

But what if this mini-black hole had too low a velocity to enable it to pass through the Earth and instead became trapped in the terrestrial gravity field? It would then fall towards the planet's centre, overshoot, fall back, overshoot again, fall back again, and so on. Because of the Earth's rotation, however, the oscillation would not be along a single line but along a series of linked tracks. The mini-black hole would therefore carve out an irregular volume from the Earth's interior, growing larger as it did so and absorbing more matter with each sweep. Thus hollowed out, the Earth would probably collapse into the black hole with a diameter of $2 \mathrm{~cm}$ and a mass and gravitational field identical to that of the planet it had destroyed.

Fantasy? Possibility? Probability? No, yes, no - in that order. As it happens, mini-black holes, black holes of less than stellar size, have not yet been detected, although they were postulated on theoretical grounds by Stephen Hawking in 1974 and to that extent are a serious scientific possibility. The chance of one of them colliding with the Earth must be regarded as remote, however, if only because if such hole-planet collisions were common there would be far fewer bodies in space than there actually are. On the other hand, annihilation of the Earth by a miniblack hole is only one of a bewildering variety of possible catastrophes, many of them less bizarre than that, through which the human species might meet its end.

Indeed, there are so many possibilities here that in his book about them Asimov has had to design a five-fold classification system in order to make the overall picture intellectually assimilable. To begin with, then, we have "Catastrophes of the First Class", defined as changes such as to 